\title{
Mechanizing People and Pedagogy: Establishing Social Presence in the Online Classroom
}

Jennifer M. Cunningham

Kent State University at Stark

\begin{abstract}
This research addresses the affordances of using Voki avatars to create a sense of social presence in an asynchronous online writing classroom setting. Digital media afford online educators the opportunity to harness different technologies and new ways of being in a digital classroom that can enhance student engagement in ways similar to yet unlike face-to-face instruction, but this current research questions the effectiveness of these technologies. Original data was obtained from forty students in an online writing course who responded to open-ended questions about their perception of social presence. This study reiterates the importance of establishing social presence in an online course, but suggests students may find specific Web 2.0 technology less effective than other pedagogical methods.
\end{abstract}

\section{Introduction}

\section{Mechanizing people and pedagogy: Establishing social presence in the online classroom}

Online classes can be impersonal and lack the simple but meaningful verbal and nonverbal cues and the overall social presence and immediate response-time that permeates traditional, face-to-face classrooms. Although approximating social presence can be a challenge in digital environments, incorporating avatars might be one way to enrich online learning. As the types of reading, writing, and ways of being continue to change in our new capitalistic world (Gee \& Hayes, 2011), so, too, should the kinds of pedagogies and techniques instructors employ. Digital media afford online educators the 
opportunity to harness different technologies and ways of replicating and, perhaps, enhancing more traditional pedagogical techniques in a digital classroom that can encourage student engagement in ways similar to, yet unlike, face-to-face instruction. This study considers the ways that a specific Web 2.0 technology might enhance or "power up" (Gee \& Hayes, 2011, p. 9) learning in online classes. Specifically, this study addresses the perceived effectiveness of using Voki avatars (www.voki.com), a specific type of Web 2.0 technology, to establish a sense of social presence (Short, Williams, \& Christie, 1976) in an asynchronous online writing class. Effectiveness is operationalized as whether students provided qualitative responses to a survey discussing or mentioning, specifically, that the use of Vokis helped create a sense of a more personalized class experience and/or helped students feel as though they connected with another person in the class, thus creating a sense of community.

\section{Community of Inquiry}

Establishing social presence is one of the biggest challenges when teaching online (Sung \& Mayer, 2012). As Wei, Chen, and Kinshuk (2012) indicate, "Lack of social presence may lead to a high degree of frustration, an unreasonably critical attitude toward the instructor's effectiveness, and a lower level of affective learning” (p. 529). Their study, among others (Gunawardena \& Zittle, 1997; Sung \& Mayer, 2012; Tu \& McIssac, 2002; Walther, 1992), found that "social presence has a high positive impact on learning” (Wei, Chen, \& Kinshuk, 2012, p. 539). Other scholars have examined concepts beyond social presence that influence successful online learning. One, in particular, worth discussing before moving on to social presence in particular is the Community of Inquiry (CoI) framework.

Garrison, Anderson, and Archer (2000) developed the CoI framework as a "process model that provides a comprehensive theoretical model that can inform both research on online learning and the practice of online instruction" (Swan, et al., 2008). The CoI framework is founded on the precept that effective online learning must develop a sense of community. According to Garrison, Anderson, and Archer (2000) there exist three elements that make up and create a CoI: cognitive presence, teaching presence, and social presence. Cognitive presence is defined as the ability to "construct meaning through sustained communication" (Garrison, Anderson, \& Archer, 2000, p. 89). The authors are careful to explain, however, that cognitive presence alone "is not sufficient to sustain a critical community of learners” (p. 94). To reinforce cognitive presence, teaching presence must also exist. Teaching presence is comprised of two functions: design and facilitation. Design "includes the selection, organization, and primary presentation of course content, as well as the design and development of learning activities and assessment" (Garrison, Anderson, \& Archer, 2000, p. 90). Facilitation is defined as "a responsibility that may be shared among the teacher and some or all of the other participants or students" (Garrison, Anderson, \& Archer, 2000, p. 90). Teaching presence supports and strengthens cognitive presence and social presence. Social presence is the third element and the one which will be investigated in the present study. Social presence is defined as "the ability of participants in the CoI to project their personal characteristics into the community, thereby presenting themselves to the other participants as 'real people'” (Garrison, Anderson, \& Archer, 2000, p. 89). In other words, social presence is "the degree to which learners feel socially and emotionally connected with others in an online environment" (Swan et al., 2008).

Garrison and Cleveand-Innes (2005) stress a CoI is comprised and created from multiple interactions among instructors, students, and the course content. A successful CoI relies on interaction, but interaction does not ensure learning. Garrison and Cleveland-Innes (2005) write:

To appreciate interaction and the quality of learning out-comes, one must understand how cognitive, social, and teaching presence come together to create a purposeful community of inquiry. An interactive community of learners is generally considered the sine qua non of higher education. However, interaction is not a guarantee that students are cognitively engaged in an educationally meaningful manner (p. 135). 
Although the CoI framework is readily applied and held in high esteem among academics, it is not without limitations. Arbaugh, Bangert, and Cleveland-Innes (2010) found that the framework might be more applicable when discussing applied disciplines rather than pure or theoretical disciplines. In other words, online classes that include mostly lectures are less relevant when applying the CoI framework than classes that require real-life application or encourage more activity and involvement among students. Likewise, Akyol and Garrison (2008) found that students perceive that they learn in online classes but that their learning tends to be lower-level learning. In this current research, students' perceptions of or actual learning is beyond the scope. Those topics tend to focus on indicators of cognitive presence. Here, the topic of focus is students' perceptions of social presence.

\section{Social Presence}

The concept of social presence was first defined by social communication studies researchers Short, Williams, and Christie (1976) as the "degree of salience of the other person in a mediated communication and the consequent salience of their interpersonal interactions" (p. 65). Later, Walther (1992) found that participants in online settings developed visual interpretations of others based on their writing to help create a sense of intimacy and identification, which inspired this present study and the inclusion of Voki avatars to help students approximate a visual interpretation of their instructor and classmates. Further reinforcing this study and the use of Voki avatars, researchers Kim, Kwon, and Cho (2011) found that media integration positively affects social presence in distance learning.

Adding to the previous definition of social presence, Gunawardena and Zittle (1997) included the idea that presence was related to whether a person felt as though he or she was interacting with a "real" person. Tu and McIssac (2002) further redefined social presence in digital environments as being able to create a "feeling of community" (p. 131) and found that social presence positively influences online instruction. They specify that social presence is the "degree of feeling, perception, and reaction to another intellectual entity in the CMC [computer-mediated communication] environment” (Tu \& McIsaac, 2002, p. 146) and include four dimensions used to establish and maintain social presence: social context, online communication, interactivity, and privacy. Addressing the importance of social presence in a learning environment, Wei, Chen, and Kinshuk (2012) wrote, "Learners must perceive an appropriate degree of social presence before feeling comfortable in interaction with others. Therefore, social presence is a key element for enhancing and fostering learning interactions in online classrooms” (p. 530).

As the definition of social presence continued to change, so, too, did the categories used to define it. For example, Aragon (2003) included three categories - course design strategies, instructor strategies, and participant strategies-while Sung and Mayer (2012) identified thirty affective indicators and five factors of online social presence. Sung and Mayer's (2012) study focused on the premise that "online learning is [or should be] an inherently social endeavor, and social interaction with the teacher and other learners is instrumental in motivating learners' efforts to learn as well as promoting their satisfaction with online courses" (p. 1738.) They associate the "fundamental nature of social presence" with "a feeling rather than reason" (p. 1738), identifying five factors that make up online students' perceptions of social presence: social respect, social sharing, open mind, social identity, and intimacy. Drawing on the available definitions, Sung and Mayer (2012) proposed that "social presence relates to whether participants [feel] they are interacting with real people when they are online" (p. 1738) and that it is "the subjective feeling of being connected and together with others during computer mediated communication” (p. 1739). This current study relies on Sung and Mayer's (2012) definition of social presence as well as Gunawardena and Zittle (1997) with attention to the need for students to feel that they are communicating with and are connected to real people as well as the ability to create a sense of community (Tu \& McIssac, 2002). 


\section{Avatars}

One potential way to achieve a sense of community and of communicating with real people, ironically perhaps, is via avatars, which provide a visual image of a digital (and, therefore, not real) person or character. In the gaming industry and some social platforms such as Second Life-a virtual world where people interact as avatars - using avatars is nothing new. Some online and hybrid classes have even been conducted virtually using Second Life. Exploring the effectiveness of using avatars for pedagogical purposes when teaching social work students about cultural competence, Lee (2014) considered using Second Life because it is "the most sophisticated virtual community on the market," but chose to incorporate Voki, because it required less time to learn to navigate and was "simple and easy to teach students" (p. 96). Lee found that using Voki avatars "present[ed] an opportunity for individuals to experience different perspectives" and "that virtual communities provide a useful and safe medium for integration of culture competence training” (p. 104). Lee's study incorporated Voki avatars in the form of a "cocktail party," asking students to choose avatars that represented roles they would play during the virtual event. In this current study, Voki were chosen as the optimal option for incorporating avatars into an online class for similar reasons as Lee. This research, however, investigates using avatars to a lesser extent than required when communicating in a virtual word or at a virtual party. The students in this study were asked to create an avatar on three separate occasions to respond to prompts on a discussion forum.

With Voki (www.voki.com), users choose from a template of options in order to create avatars in the likeness of themselves, animals, historical figures, and other characters. Users can choose to add a text-to-speech voice message in several masculine and feminine voices and accents or record their own voice message using a microphone. Although these avatars do not accommodate or recreate facial cues, their creators' choices in character, clothing, and style (e.g., hair color and style, accessories, etc.) allow for some insight into the students' personalities, tastes, and likenesses. Additionally, if users choose to record their voices, verbal cues like tone and inflection are more apparent. With all of this in mind, including avatars could be one way to establish social presence - to help make physical the innate desire to imagine an image and voice when communicating in a more removed or abstract setting such as learning in an online classroom. This conception of social presence also assumes that including visual and auditory cues will establish a sense of a "real" person as well as a sense of community.

\section{Methodology}

\section{Participants}

The participants in this study all attended the same large, Midwestern community college and all completed the same online writing class with the same instructor. Students in this particular writing course were asked to create talking avatars and post them to discussion forums on three separate occasions throughout the semester. All students in the course were required to create a Voki, which they used when participating in class discussions. On each occasion, students could change the appearance and accent or voice of their avatars. No features were automatically saved for future use, so students had to recreate their chosen characters for each discussion forum activity. Students responded to questions and prompts by creating their avatars, recording their response, and embedding their chosen Voki character within a discussion forum. Once embedded, the avatars would play on command whatever recorded message each student had prepared.

Participants were students in a college's pre-requisite composition class (College Composition II) during one of three semesters. This course was offered face-to-face and online and all participants were students in the online version of this class with the same instructor. Seven total sections of the course were included in the data collection: two sections during the Spring semester, three sections in the Summer semester, and two sections from the Fall semester. All students who took this course during 
these three semesters were invited to participate in the survey once the semester ended. Students were contacted once they had completed the course and grades had been posted. The project and consent form had also been approved by the Institutional Review Board (IRB). By the end of the third and final semester of data collection, 40 self-selected student participants out of a possible 140 students total participated. Students self-selected in that they chose to, but were not required to, respond to a questionnaire after indicating interest and consenting based on an email sent to them after grades were posted and they were no longer students in the class.

The questionnaire was adapted from Gunawardena and Zittle’s (1997) and Richardson and Swan's (2003) social presence surveys about their overall experience with social presence in this particular online class as well as the potential affordances of incorporating Voki avatars to establish social presence. Eleven male students and 29 female students chose to participate and complete the survey. Their mean age was 31.9 years with an age range of 18-49 years. This specific course was the first online class (of any subject at any university) for six of the participants, 15 participants indicated that they had taken between two to four other online classes, nine survey participants had taken between five to six online classes, one participant had taken nine online classes, and four participants had taken 10 or more online classes.

\section{Open-ended Questions}

Participants were given a newly-created survey that was adapted from Part I of Richardson and Swan's (2003) survey, modified from Gunawardena and Zittle's (1997) survey, which examined social presence in computer mediated conferences. The first part of the survey asked about social presence in general and the second part of the survey asked the same questions but as they related to Vokis specifically. This adapted survey also included three additional open-ended questions, not included in either of the previous surveys, which are the focus of this present research. The hypothesis was that students would make mention of the Voki avatars when answering open-ended questions, particularly when answering question 2 below, because students were asked to create, watch, and respond to their peers' avatars. In that way, the following hypothesis guided this research and research questions:

$\mathrm{H}$ 1. Participants will perceive that visual and auditory aspects afforded via creating and watching Voki avatars played a significant role in establishing and maintaining social presence in this current online class, and, therefore, will make mention of Vokis when responding to the current research survey's openended questions, indicating that Vokis, specifically, helped create a sense of social presence.

The three open-ended questions are the focus of this current research. Their purpose was to better understand the kinds of course activities and assignments students felt better-established social presence and facilitated learning. The open-ended questions are as follows:

Please explain what, if anything, best helped you feel like you were more than just a number in this class.

Please explain what, if anything, helped you feel like you became acquainted with fellow students in this class.

Please include any other comments or feedback that you have not been able to express yet but would like to.

Question 1 relates to the first phase or earlier definition of social presence, which focused on salience of interpersonal relationships. Question 2 relates to the second phrase or later definition of social presence, which addresses the importance of feeling as though a student is interacting with a real person. Question 3 
was included to allow participants a space to include any other information that they deemed relevant or important.

\section{Analysis and Reliability}

To analyze the responses obtained from the open-ended questions, content analysis (Berelson, 1952; Hsieh \& Shannon, 2005; Krippendorff, 2004; Neuendorf, 2002), informed by grounded theory (Glaser \& Strauss, 1967), was applied. Open coding began by reading through all student responses, looking for patterns among the feedback. Comments were coded according to topics discussed within each response. Consider the following three examples to the first question, "Please explain what, if anything, best helped you feel like you were more than just a number in this class":

The instructor's thorough feedback on our essays.

I liked how the instructor was very personal in all of her responses and emails.

A lot of interaction with your peers and emails from the professor kept the class interesting

The topics mentioned in each response became the categories. In other words, in Example 1, the topic is "instructor's feedback," which is easier to determine because the statement is short and focused. In this example, the topic "instructor feedback" was categorized as Feedback. Example 2 includes both “instructor's responses” (categorized as Essay Feedback from Instructor) and "email from instructor," which was categorized as Email from Instructor. Example 3 also includes two topics: "interaction with peers" (categorized later as Peer Workshop/Review) and "email from instructor," which, again, was categorized under that same name. Each of the responses were coded and categorized likewise for Question 2 and Question 3.

Question 1 yielded 7 categories: Email from Instructor, Essay Feedback from Instructor, Other/Vague, Peerworkshop/Review, Discussion Forum, Voki, and Nothing. Inter-rater reliability simple agreement and Cohen's Kappa when coding responses for Question 1 were .93 and .90, respectively. Question 2 yielded 6 categories: Group/Collaborative Project, Peer Workshop/Review Feedback, Discussion Forum, Voki, Emailing with Students, Other/Vague. Inter-rater reliability simple agreement and Cohen's Kappa when coding responses for Question 2 were .90 and .91, respectively. Question 3 yielded 7 categories: Accolades for Instructor, No Vokis, Accolades for Course, Unhappy with Course, Liked Voki, Statement Regarding Online Class, Other/Vague. Inter-rater reliability simple agreement and Cohen’s Kappa when coding responses for Question 3 were .90 and .90.

\section{Results}

Table 1 (next page) includes the coded and categorized results regarding participants' perceptions of individual attention online or what made them feel like "more than just a number" when communicating in an asynchronous online class. As evident from Table 1, students thought receiving individual emails from their instructor was the most important factor that helped them feel more individualized within this class, followed by the feedback the instructor included on student essays. There was no expectation or hypothesis regarding how students would answer Question 1. However, Vokis were anticipated to be mentioned since they afforded students the ability to personalize their avatars. The number of times the instructor was mentioned was not anticipated, but correlates with previous research, which will be discussed below in Instructor Presence and Immediacy. The majority of students discussed the importance of detailed, relevant, and timely instructor responses, indicating that, in order to feel as though they "matter," students appreciated and somewhat expected the instructor to have a prominent presence online, 
responding to individual emails timely and respectfully and mentioning students by name or referencing class-specific ideas or comments when responding to group emails.

Table 1 Perception of Individuality Online

Question: Please explain what, if anything, made you feel like more than just a number in this class.

Category

Email

Instructor

\section{Definition}

from The student indicated that individual email responses from the instructor helped him or her feel less like a number in this online class. Essay Feedback from
Instructor

Other/Vague

Peer Workshop/Review

Discussion Forum

Voki

Nothing
The student indicated that individual essay feedback directly from the instructor helped him or her feel less like a number in this online class.

The student included a general statement that was too vague to categorize.

The student indicated that participating in Peer Workshop/Review where small groups of students uploaded their essays to a forum, reading and providing feedback for each of their group members helped him or her feel less like a number in this online class.

The student indicated that Discussion Forums between students where they were expected to post and discuss topics helped him or her feel less like a number in this online class.

The student indicated that creating and watching Voki avatars (Web 2.0 technology that allows students to choose historical, animal, and various other characters and add a recorded or textto-speech voice message) helped him or her feel less like a number in this online class.
Frequency $\mathrm{n}=31$ *

$15(48 \%)$

$12(39 \%)$

$6(19 \%)$

$5(16 \%)$

$5(16 \%)$

$2(6 \%)$

$1(3 \%)$

less like a number in this online class.

*Note: Frequency count is higher than $n$ because some students listed or included more than one item in their responses.

Although feeling like an individual and receiving personalized attention is important, feeling like part of a community is also important to students and vital to creating a sense of social presence, which leads to the second question and responses found in Table 2 (next page). 
Table 2 Perception of Social Presence Online

Question: Please explain what, if anything, helped you feel like you became more acquainted with fellow students in this class.

\begin{tabular}{|c|c|c|}
\hline Category & Definition & $\begin{array}{l}\text { Frequenc } \\
\mathbf{n}=33^{*}\end{array}$ \\
\hline $\begin{array}{l}\text { Group/Collaborative } \\
\text { Project }\end{array}$ & $\begin{array}{l}\text { The student indicated that participating in the } \\
\text { group/collaborative project with other students in the class } \\
\text { helped him or her become more acquainted with fellow } \\
\text { students. }\end{array}$ & $13(39 \%)$ \\
\hline $\begin{array}{l}\text { Peer } \\
\text { Workshop/Review } \\
\text { Feedback }\end{array}$ & $\begin{array}{l}\text { The student indicated that participating in Peer } \\
\text { Workshop/Review where small groups of students uploaded } \\
\text { their essays to a forum, reading and providing feedback for } \\
\text { each of their group members helped him or her become more } \\
\text { acquainted with fellow students. }\end{array}$ & 12 (36\%) \\
\hline Discussion Forum & $\begin{array}{l}\text { The student indicated that participating in Discussion Forums } \\
\text { with other students in the class helped him or her become more } \\
\text { acquainted with fellow students. }\end{array}$ & $6(18 \%)$ \\
\hline Voki & $\begin{array}{l}\text { The student indicated that creating and watching Voki avatars } \\
\text { (Web } 2.0 \text { technology that allows students to choose historical, } \\
\text { animal, and various other characters and add a recorded or } \\
\text { text-to-speech voice message) with other students in the class } \\
\text { helped him or her become more acquainted with fellow } \\
\text { students. }\end{array}$ & $6(18 \%)$ \\
\hline $\begin{array}{l}\text { Emailing } \\
\text { Students }\end{array}$ & $\begin{array}{l}\text { The student indicated that communicating via email with other } \\
\text { students in the class helped him or her become more } \\
\text { acquainted with fellow students. }\end{array}$ & $2(6 \%)$ \\
\hline Other/Vague & $\begin{array}{l}\text { The student included a general statement about the course or } \\
\text { instructor that was too vague to categorize. }\end{array}$ & $2(6 \%)$ \\
\hline
\end{tabular}

*Note: Frequency count is higher than $n$ because some students listed or included more than one item in their responses.

Although Vokis were hypothesized to play a larger role in establishing social presence, more direct, interpersonal communication between students seemed to be more significant. Further, participants were expected to dislike the collaborative group project assigned for this particular class, given the difficulty of working in groups with the added complexity of working asynchronously online. Perhaps students did dislike the collaborative group project, but, nevertheless, the majority of students who responded to this question found it to be the most valuable in creating social presence. Peer workshops, too, played a significant role, and, again, students were expected to dislike or fail to understand the value in reading and responding to group members' essays in an asynchronous environment via a discussion board. However, students indicated that they enjoyed this activity and that reading their peers' essays helped them feel more connected to their classmates. 
Participants were also asked to include any additional comments or feedback that they were not already able to discuss in the previous two questions. Table 3 includes the students' open-ended responses.

Table 3 Additional Comments or Feedback

Question: Please include any other comments or feedback that you have not been able to express yet but would like to.

\begin{tabular}{|c|c|c|c|}
\hline Category & & Definition & $\begin{array}{l}\text { Frequenc } \\
\mathbf{n}=20^{*}\end{array}$ \\
\hline $\begin{array}{l}\text { Accolades } \\
\text { Instructor }\end{array}$ & for & $\begin{array}{l}\text { The student included a general or specific statement praising the } \\
\text { instructor. }\end{array}$ & $8(40 \%)$ \\
\hline No Vokis & & The student indicated that creating Voki avatars was not helpful. & $5(25 \%)$ \\
\hline $\begin{array}{l}\text { Accolades } \\
\text { Course }\end{array}$ & for & $\begin{array}{l}\text { The student included a general or specific statement praising this } \\
\text { particular online class. }\end{array}$ & $4(20 \%)$ \\
\hline $\begin{array}{l}\text { Unhappy } \\
\text { Course }\end{array}$ & with & $\begin{array}{l}\text { The student indicated that he or she was unhappy with at least } \\
\text { one aspect of this course, other than the Vokis which are } \\
\text { included as a separate category. }\end{array}$ & $2(10 \%)$ \\
\hline Liked Voki & & $\begin{array}{l}\text { The student indicated that he or she enjoyed creating Voki } \\
\text { avatars or found them useful. }\end{array}$ & $1(5 \%)$ \\
\hline $\begin{array}{l}\text { Statement } \\
\text { Regarding } \\
\text { Class }\end{array}$ & Online & $\begin{array}{l}\text { The student included general information about his or her } \\
\text { experiences with online learning. }\end{array}$ & $1(5 \%)$ \\
\hline Other/Vague & & $\begin{array}{l}\text { The student included a statement that did not include any } \\
\text { comments or feedback. }\end{array}$ & $1(5 \%)$ \\
\hline
\end{tabular}

*Note: Frequency count is higher than $n$ because some students listed or included more than one item in their responses.

As evidenced in Table 3, a strong instructor presence was important to these students, which they reiterated when discussing the instructor's timely email responses (24-hour response time) and detailed, individualized feedback on essays. For these students, timely (i.e., email) and individualized (i.e., feedback) attention seemed to be all that was necessary for instructor presence to be regarded as high and satisfactory. Also as evidenced in Table 3, students found less value in creating and using Vokis than anticipated.

\section{Discussion}

This study found that, in this specific online class, the use of Voki avatars did not play a significant role in establishing social presence or creating a sense of community. Although there are many characteristics and factors that constitute social presence, this study relies on a conflation and expansion of many scholars' concepts (especially Ke, 2010; Stacey, 2002; Sung \& Mayer, 2012) in order to make sense of what these specific students found to establish social presence. Initially, this research 
hypothesized that incorporating Voki avatars would significantly increase students' perceptions of social presence, but other factors seem to play a larger role. Sung and Mayer (2012), as discussed previously, mention many of the varying factors, also including two particular factors relevant to this study. They write,

The degree of online social presence is based on the characteristics of the medium and the user's perception. These are associated with two components of online social presence, which are intimacy and immediacy.... According to a large number of studies in online social presence, intimacy and immediacy are good predictors or potential indicators of student's online learning. (p. 1739)

With this current research, the characteristics of the medium (e.g., email) and users' perceptions (e.g., quick email replies from the instructor) played the biggest role in establishing social presence. Swan, Richardson, Ice, Garrison, Cleveland-Innes, and Arbaugh (2008) conducted a factor analysis, concluding that "an online community of inquiry emerges out of social, cognitive and teaching presence" and that "[s]tudent responses to statements about his or her online experiences clustered around items as defined by the theory." Likewise, this current research found that students' qualitative comments tended to cluster around the same items, specifically, teaching presence and social presence. Just as Sung and Mayer (2012) found, intimacy and immediacy seemed to be prominent indicators of a student's sense of social presence, this current research suggested likewise. Although social presence is much more complex than two simplified characteristics, the data obtained in this current study can be categorized with those specific factors in mind. However, rather than intimacy (Sung \& Mayer, 2012), these current data suggest that instructor presence and interactivity along with the underlying necessity for immediacy help establish social presence in an online mediated learning environment.

\section{Instructor Presence and Immediacy}

The findings for Question 1 and 3 speak directly to teaching presence, categorized here as Instructor Presence and Immediacy, much like the category of teaching presence discussed in the CoI framework. Students indicated that, overall, the instructor's feedback and quick responses helped them feel like "more than just a number in this class." Much of the previous research, likewise, has indicated the importance of instructor presence in relation to establishing a CoI. Garrison and Cleveland-Innes (2005) argue that "teaching presence is important for the creation and sustainability of a community of inquiry focused on the exploration, integration, and testing of concepts and solutions (p. 135) and that "teaching presence contributes to the adoption of a deep approach to learning and that interaction by itself does not promote a deep approach to learning” (p. 140).

Richardson and Swan (2003) found that the instructor was one of the most essential aspects when investigating students' perception of social presence. Likewise, Stacey (2002) found that the instructor's role was "a major factor" in the success of online learning. Ke (2010) examined social presence in online classes, specifically focusing on adult learners, finding that "teaching presence should be the catalyst that initiates the community development process" (p. 817). This current study reinforces what these previous scholars found. Ke (2010) also found that "adult students have identified instructors who demonstrated high presence online as the key to learning satisfaction," which included providing "prompt and meaningful" feedback (p. 817). Likewise, the students' comments in this study reiterated the fact that they found the instructor to be instrumental in that Email from Instructor and Instructor Feedback were the most mentioned items that helped the students feel as though they had an individual learning experience with a real person.

Garrison and Cleveland-Innes (2005) suggest that social presence by itself and the exchange of information alone cannot create meaningful learning. Instead, "[t]eaching presence provides the structure (design) and leadership (facilitation/direction) to establish social and cognitive presence (i.e., community 
of inquiry)” (p. 144). They suggest, then, that simple interaction—absent of structure and leadership-is not enough to create social presence. A lack of structure and leadership might explain why Vokis were less successful than other aspects of the class that had more structure and leadership. Specifically, in this class, "purposeful and systematic discourse," an important component when discussing a CoI and social presence, was present in other facets of the class such as peer workshops and essays submissions along with feedback but less so when creating and embedding Vokis in a discussion forum (Garrison \& Cleveland-Innes, 2005, p. 135).

\section{Interactivity}

Perhaps not surprising (though, unexpected in this research) is the role group work-small group discussions, peer feedback, and a collaborative project-played in establishing social presence. Answering Question 2, students indicated that group work and interacting directly with their peers helped them feel more acquainted with other students. Stacey (2002) found that collaborative learning enhanced overall online learning (p. 293). Similarly, Kim, Kwon, and Cho (2011) found that student demographics and previous online experience mattered little regarding students' perceptions of social presence; however, "evidence showed that both social presence and learning satisfaction are affected by media integration and quality instruction" and that "[i]nteractivity was found to be a good predictor of social presence" (p. 1517). Likewise, Akyol and Garrison (2008) analyzed social presence over time in messages posted in a discussion board during a graduate course, finding that "some of the students' responses to open-ended questions also confirmed the importance of collaborative activities for their learning” (p. 16). Social presence is necessary for collaborative projects to be effective (Garrison, 2007) but collaborative projects, according to this study, may also help establish and maintain social presence. As Garrison (2007) writes, "The purpose of social presence in an education context is to create the conditions for inquiry and quality interaction (reflective and threaded discussions) in order to collaboratively achieve worthwhile educational goals” (p. 64).

This finding shows that, perhaps, the interactions and not the technology are what matter. In this way, a better research question might have been whether avatars support interactions and group work. This current research incorporated Vokis among more individualized activities such as discussion forums, asking students to post one and listen to/watch two other students' posts and respond. Perhaps if communication were extended to ongoing interaction among students, the usefulness and perception of Vokis might have changed or been more prominent. Again, the positive responses regarding peer workshops were unexpected, so future research could attend to a more specific focus on the ways that Vokis or avatars in general might be used when incorporating peer workshops or whether incorporating avatars among group work changes the perceived effectiveness of the activity at all.

\section{Limitations}

Within this study, there are three major limitations. The first limitation is the small sample size of 40 participants. Ideally, a higher participation rate would have allowed for more diverse opinions. Out of a total of 140 students who completed the course and were emailed asking to participate, only 40 students (29\%) self-selected to complete the survey. Allowing students to self-select was important in achieving more valid results, because students were not required to participate and were not asked to participate until after their respective semesters had ended. The second major limitation was that this course was developed and taught by one instructor, which, again, does not allow for true diversity or broadness of perspectives. However, even though data was collected from one instructor's class, the findings provide a foundation for further discussion about social presence in online classroom environments and allow for higher internal validity, since each of the classes would have been taught similarly by the same instructor. The third limitation was that there was no control group with which to compare data. Each of the participants included in the data set were students in a class that incorporated Vokis. The data is still 
worthwhile, suggesting that there is a correlation between participants who used Vokis and finding other kinds of communication more valuable when establishing social presence. Future research could include a pre- and post-survey about with two different groups of participants: one who completed a class that incorporated Vokis and one that completed a class without Vokis. Group feedback could be compared in order to establish a correlation between the perception of social presence when considering classes that incorporate Voki avatars and those that do not.

\section{Conclusion}

In sum, instructor presence and interactivity when combined with immediacy help online students feel as though they are communicating with real people in a timely and practical manner, creating a sense of community. Applied subjects fare better online in terms of social presence than pure subjects. As Arbaugh, Bangert, and Cleveland-Innes (2010) found, their research

suggests the possibility that the CoI framework may be more applicable to applied disciplines than pure disciplines. The CoI's assumption of a constructivist approach to teaching and learning may not align with the cumulative, instructor-oriented approaches particularly associated with hard, pure disciplines. (p. 43)

In that way, I would argue that writing is an applied subject, and, unlike lecture-based courses, includes peer workshops and instructor feedback, which all reinforce a CoI.

The concept of social presence and the CoI might not work well in some classes, as Rourke and Kanuka (2009) argue, "CoI fails as a model for achieving deep and meaningful learning because the procedures for achieving those outcomes do not materialize” (p. 43). Achieving social presence might not work well in some classes, but I would argue that a CoI works well in a composition class-perhaps better without avatars, or, at least, the way that avatars were applied within this particular class. Deep and meaningful thinking happened outside of the discussion forum, often, when students were writing and revising essays after receiving feedback from their peers and instructor.

Particular Web 2.0 technology such as Voki avatars seems to matter less to students than a responsive, attentive instructor and the ability to work collaboratively with other students in the online environment. Although incorporating Vokis into this online class was entertaining for some students, taking the time to create a talking avatar for each of the assigned discussion forums seemed pointless or annoying to others. The way that Vokis were incorporated into this class, essentially, was less "real" than directly communicating with other students and the instructor via email and peer workshops. Here, then, text-based communication was more effective in creating a sense of community than a visual and auditory representation that took more time and effort to create. Perhaps if avatars were incorporated in a more robust and regular manner (i.e., the way avatars are used in Second Life), then students might have found the use of avatars to be more helpful and capable of producing a sense of community and social presence. Regardless of whether instructors should include Voki avatars in online classes if the avatars help the instructor establish the kind of social presence Walther (1994) suggests by envisioning what students might look like or enjoy (e.g., dog-lovers tend to choose dog avatars), it is clear that there are other factors that help establish social presence. From the qualitative data collected and analyzed in this study, there are two major factors in creating social presence. First, it seems there needs to be a present and responsive instructor who can provide relevant feedback via emails, discussion forums, and on essays in a timely manner. And, the second important factor seems to be the ability to work with other students in small groups and on larger projects in ways that are direct and pragmatic. Overall, this research suggests that the instructor's presence and interacting with other students establishes more social presence than any talking dog or cartoon character is capable of doing on its own. 


\section{References}

Akyol, Z. \& Garrison, D. R. (2008). The development of a Community of Inquiry over time in an online course: Understanding the progression and integration of social, cognitive, and teaching presence, Journal of Asynchronous Learning Networks, 12(3-4), 3-22.

Aragon, S. R. (2003). Creating social presence in online environments. In Aragon, S. R. (Ed.), New directions for adult and continuing education: Facilitating learning in online environments, (Vol. 100, pp. 57-68). Hoboken, NY: Wiley.

Arbaugh, J. B., Bangert, A., \& Cleveland-Innes, M. (2010). Subject matter effects and the Community of Inquiry (CoI) framework: An exploratory study, Internet and Higher Education, 13, 37-44.

Berelson, B. (1952). Content analysis in communication research. New York: Free Press.

Garrison, D. R. (2007). Online community of inquiry review: Social, cognitive, and teaching presence issues. Journal of Asynchronous Learning Networks, 11(1), 61-72.

Garrison, D.R., Anderson, T., Archer, W. (2000). Critical inquiry in a text-based environment: Computer conferencing in higher education. The Internet and Higher Education, 2, 87-105.

Garrison, D. R., \& Cleveland-Innes, M. (2005). Facilitating cognitive presence in online learning: Interaction is not enough, The American Journal of Distance Education, 19(3), 133-148.

Gee, J. P., \& Hayes, E. R. (2011). Language and learning in the digital age. New York: Routledge.

Glaser, B. G., \& Strauss, A. L. (1967). The discovery of grounded theory. Chicago: Aldine Publishing Company.

Gunawardena, C. N., \& Zittle, F. J. (1997). Social presence as a predictor of satisfaction within a computer-mediated conferencing environment. The American Journal of Distance Education, 11(3), 8-26.

Hsieh, H., \& Shannon, S. E. (2005). Three approaches to qualitative content analysis. Qualitative Health Research, 15(9), 1277-1288.

Inman, J. A. (2004). Computers and writing: The cyborg era. Mahwah: Lawrence $\quad$ Erlbaum Assoc.

Ke, F. (2010). Examining online teaching, cognitive, and social presence for adult students. Computers and Education, 55, 808-820.

Kim, J., Kwon, Y., \& Cho, D. (2011). Investigating factors that influence social presence and learning outcomes in distance higher education. Computers \& Education, 57(2), 1512-1520.

Kress, G. (2003). Literacy in the new media age. New York: Routledge.

Krippendorff, K. (2004). Content analysis: An introduction to its methodology. Thousand Oaks, CA: Sage Publications.

Landow, G. P. (1992). Hypertext 3.0: Critical theory and new media in an era of globalization. Baltimore: Johns Hopkins UP. 
Lankshear, C. \& Knobel, M. (2008). New literacies: Everyday practices \& classroom learning, 2nd Ed. New York: Open University Press.

Lee, E. O. (2014). Use of avatars and a virtual community to increase cultural competence. Journal of Technology in Human Services, 32, 93-107.

Neuendorf, K. A. (2002). The content analysis guidebook. Thousand Oaks, CA: Sage Publications.

Richardson, J. C. and K. Swan. (2003). Examining social presence in online courses in relation to students' perceived learning and satisfaction. Journal of Asynchronous Learning Networks, 7(1), 68-88.

Rourke, L. \& Kanuka, H. (2009). Learning in communities of inquiry: A review of literature. Journal of Distance Education, 23(1), 19-48.

Self, C. L. (2007). Multimodal composition: Resources for teachers. Cresskill: Hampton Press, Inc.

Short, J. E., Williams, E., \& Christie, B. (1976). The Social Psychology of Telecommunications. Toronto: Wiley.

Schunk, D. H., Pintrich, P. R. \& Meece, J. (2008). Motivation in Education: Theory, Research, and Applications (3rd ed). Upper Saddle River, NJ: Pearson.

Stacey, E. (2002). Social presence online: Networking learners at a distance. Education and Information Technologies, 7(4), 287-294.

Sung, E., \& Mayer, R. E. (2012). Five facets of social presence in online distance education. Computers in Human Behavior, 28, 1738-1747.

Swan, K. P., Richardson, J. C., Ice, P., Garrison, D. R., Cleveland-Innes, M., \& Arbaugh, J. B. (2008). Validating a measurement tool of presence in online communities of inquiry, E-mentor 2(24). http://www.e-mentor.edu.pl/artykul/index/numer/24/id/543

Tu, C. H., \& McIssac, M. (2002). Relationship of social presence and interaction in online classes. The Journal of Distance Education, 16(3), 131-150.

Tyner, K. (1998). Literacy in a digital world: Teaching and learning in the age of information. Mahwah: Lawrence Erlbaum Assoc.

Walther, J. (1994). Interpersonal effects in computer mediated interaction. Communication Research, 21(4): 460-487.

Wei, C., Chen, N., \& Kinshuk. (2012). A model for social presence in online classrooms. Education Technology Research and Development, 60, 529-545.

Wysocki, A. F., Johnson-Eilola, J., Selfe, C. L., \& Sirce, G. (2004). Writing new media: Theory and applications for expanding the teaching of composition. Logan: Utah State UP. 